Florida International University FIU Digital Commons

FIU Electronic Theses and Dissertations

University Graduate School

5-19-2011

\title{
The Impact of Likability on Memory Conformity for Images
}

Jenna M. Kieckhaefer

Florida International University, jkiec001@fiu.edu

DOI: $10.25148 /$ etd.FI1 1072510

Follow this and additional works at: https://digitalcommons.fiu.edu/etd

\section{Recommended Citation}

Kieckhaefer, Jenna M., "The Impact of Likability on Memory Conformity for Images" (2011). FIU Electronic Theses and Dissertations. 426.

https://digitalcommons.fiu.edu/etd/426

This work is brought to you for free and open access by the University Graduate School at FIU Digital Commons. It has been accepted for inclusion in FIU Electronic Theses and Dissertations by an authorized administrator of FIU Digital Commons. For more information, please contact dcc@fiu.edu. 


\title{
FLORIDA INTERNATIONAL UNIVERSITY
}

Miami, Florida

\section{THE IMPACT OF LIKABILITY ON MEMORY CONFORMITY FOR IMAGES}

\author{
A thesis submitted in partial fulfillment of the \\ requirements for the degree of \\ MASTER OF SCIENCE \\ in \\ PSYCHOLOGY \\ by \\ Jenna Kieckhaefer
}




\section{To: Dean Kenneth Furton}

College of Arts and Sciences

This thesis, written by Jenna Kieckhaefer, and entitled The Impact of Likability on Memory Conformity for Images, having been approved in respect to style and intellectual content, is referred to you for judgment.

We have read this thesis and recommend that it be approved.

$\frac{\text { Stephen Charman }}{\text { Nadja Schreiber Compo }}$

Date of Defense: May 19, 2011

The thesis of Jenna Kieckhaefer is approved.

\begin{tabular}{r}
$\begin{array}{c}\text { Dean Kenneth Furton } \\
\text { College of Arts and Sciences }\end{array}$ \\
\hline Interim Dean Kevin O’Shea \\
University Graduate School
\end{tabular}

Florida International University, 2011 


\section{ACKNOWLEDGMENTS}

I wish to express my sincere gratitude to everyone who has contributed to the completion of this work. To my Major Professor, Dr. Daniel Wright, thank you for sharing your knowledge and for offering your guidance over this entire process. To Dr. Steve Charman and Dr. Nadja Schreiber Compo, my committee members, thank you for your support and contributions to this project.

I must also thank my research assistants: Kristina Artigas, Elizabeth Dehaan, Maria Isaza, and Maria Silva. I could not have finished this project without all of your hard work and excellent acting skills.

I would also like to thank my parents, Bill and Pat Kieckhaefer, for always helping me reach my academic goals and pushing me to do more. 
ABSTRACT OF THE THESIS

THE IMPACT OF LIKABILITY ON MEMORY CONFORMITY FOR IMAGES

by

Jenna Kieckhaefer

Florida International University, 2011

Miami, Florida

Professor Daniel Wright, Major Professor

The purpose of my research was to examine the impact of likability between two previously unacquainted individuals on memory conformity. One hundred and twenty seven undergraduate students were assigned to a likability condition (control, likable, or dislikable). After the likability manipulation the pair viewed pictures and were later tested on their memory for those pictures. The research confederate always answered first, so the participant's responses could be based on a combination of their memory for the event and what the confederate reported.

Results indicated that participants were most likely to conform to the confederate's responses when in the dislikable condition. Participants were most likely to answer accurately when in the likable condition. Although contrary to the previous research examining memory conformity among friends and romantic partners, these results are supported by the rapport-building literature in which creating a comfortable relationship between two strangers results in more accurate recall. 


\section{TABLE OF CONTENTS}

CHAPTER

PAGE

I. LITERATURE REVIEW .................................................... 1

Post Event Information....................................................... 1

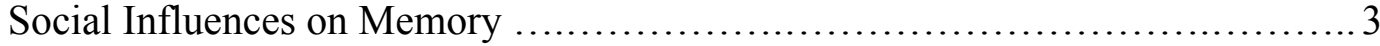

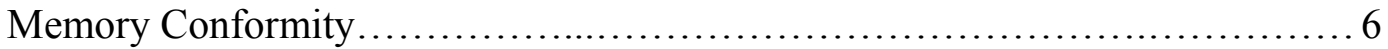

Informational Influences on Memory Conformity.............................. 7

Normative Influence on Memory Conformity................................... 8

Prior Relationships and Memory Conformity ................................ 10

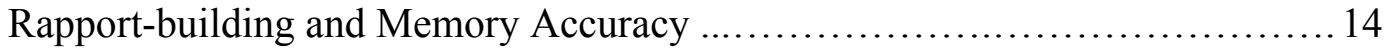

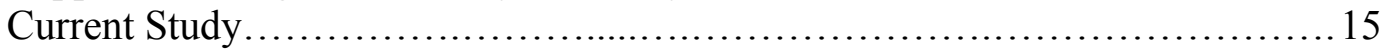

II. METHODOLOGY............................................................ 18

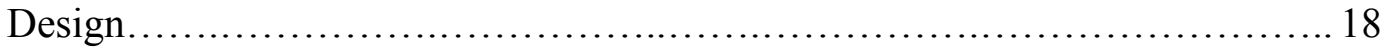

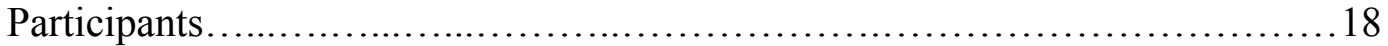

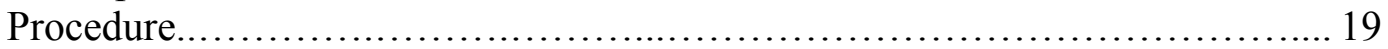

Liking Manipulation............................................................ 20

Disliking Manipulation................................................... 20

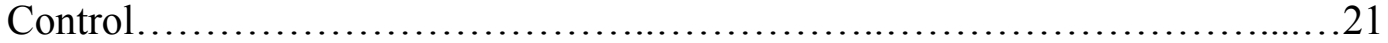

Presentation of Stimuli................................................. 21

Social Recognition Test ................................................. 22

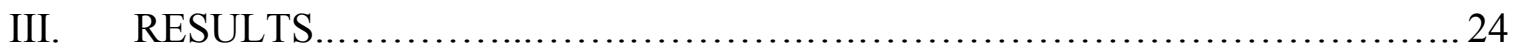

Pilot Tests of Stimulus Materials.........................................24

Preliminary Analyses...................................................... 25

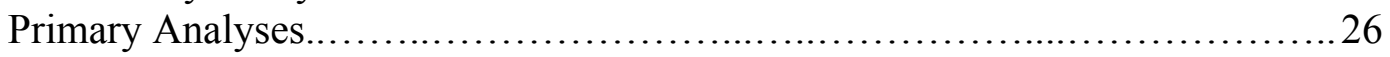

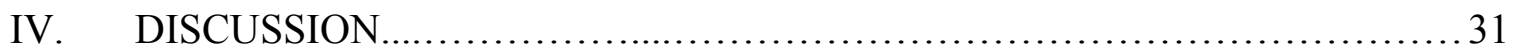

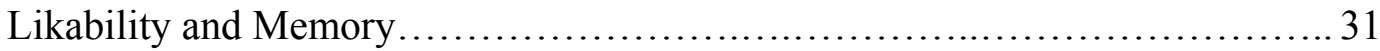

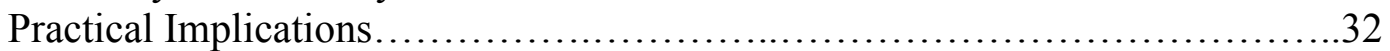

Limitations and Future Directions............................................. 33

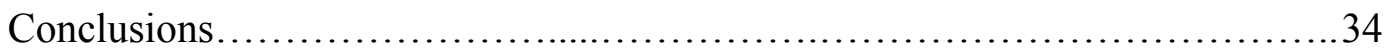

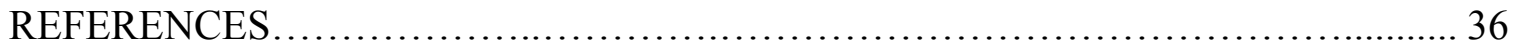

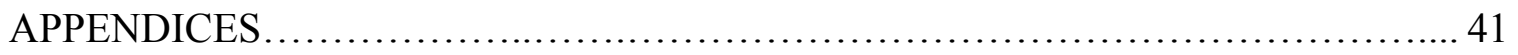




\section{Chapter I}

\section{LITERATURE REVIEW}

\section{Post Event Information}

We discuss events with all types of people. We talk with a friend about the big game. We talk with a classmate about the lecture last week. We talk with a fellow witness about the crime that was just committed. Sometimes the partner in this conversation is someone with whom we have a previous relationship, like a friend or romantic partner, and sometimes the other person is a stranger. Studies have found that discussing an event with a friend or romantic partner can lead a person to report information acquired from their partner more than if discussing an event with a stranger, otherwise known as memory conformity (French, Garry, \& Mori, 2008; Hope, Ost, Gabbert, Healy, \& Lenton, 2008). Sometimes, however, through witnessing an event together two previously unacquainted strangers can build liking or disliking for one another. Still remaining unknown is what happens when likability becomes involved in a co-witness relationship, meaning that the two are no longer strangers but they are unlikely to be considered friends. Likability may prove to be an important aspect that affects memory conformity and it might account for the French et al. (2008) and Hope et al. (2008) findings.

Although people may witness the exact same event it does not mean that they will recall the same information. Many people think memory is analogous to a tape recorder or computer program that stores all the information that it receives in the exact manner it was received (Roediger, 1980). This is not the case, however. People do not encode all the information they perceive nor do they recall everything they encode, as a result of 
differences in attention and ability to recall details. Discussions of shared events will thus often contain accurate and inaccurate information that was not originally encoded, which is called post-event information (PEI). PEI can then become encoded and incorporated into a person's memory for an event (Gabbert, Memon, \& Allan, 2003; Gabbert, Memon, Allan, \& Wright, 2004; Garry, French, Kinzett, \& Mori, 2008; Hoffman, Granhag, See, Kwong, \& Loftus, 2001; Paterson \& Kemp, 2006; Wright, Self, \& Justice, 2000). Assuming the PEI is accurate, discussion could lead to a more detailed and accurate accounting of the event. In the justice system, however, even adding additional correct information can be problematic because it may alter what the witness remembers. For example, if the witness was asked to recall what happened in the original event after speaking with another witness, this person may inadvertently include information from their fellow witness that they did not actually experience themselves. These potential alterations of memory may compromise the witness's ability to definitively assert what is accurate because the witness does not have the memory for the event in question.

Inaccurate information may also be present in discussions of a shared event. This information can be incorporated into memory like accurate information. The recollection of this inaccurate PEI is often referred to as the misinformation effect (Tousignant, Hall, \& Loftus, 1986). Misinformation via PEI can be introduced in one of three forms (Wright \& Davies, 1999). The first is through the wording of questions. Loftus (1975) used this form through asking participants biasing questions that contained some inaccurate words about the original witnessed event. Participants who were asked questions with false details more often reported actually seeing these details than people 
not presented with the false information. A second form of introducing PEI is through a re-description of the original event in which accuracy is manipulated. Vallano and Schreiber Compo (in press) used this method through giving participants a police report describing the event after they had already witnessed it. Some participants received accurate police reports and others received police reports that contained ten pieces of inaccurate PEI. Studies using this method have also shown that PEI is often incorporated into witness memory reports (Loftus, 2005). The third way that PEI can be introduced, the one of most concern for the current study, is presentation by another person. These studies usually consist of a pair of people being shown an event and then are later tested on their memory for that event. The PEI can be presented during a free dialogue or through the Social Recognition Test (SRT) procedure in which the other person presents the PEI as answers to a recognition test prior to the other person responding. In the SRT one of the people is selected to respond first, and then the second person responds. Since the first person can be a combination of both accurate and inaccurate across all stimuli, the second person may be exposed to both accurate and inaccurate PEI. These studies find that what the first person indicates as the correct answer influences what the second person reports (Wright, Memon, Skagerberg, \& Gabbert, 2009). This idea is often referred to as both memory conformity (Wright, Self, \& Justice, 2000) and social contagion of memory (Meade \& Roediger, 2002; Roediger, Meade, \& Bergman, 2001). The term memory conformity is used throughout the remainder of this paper.

\section{Social Influences on Conformity}

An examination of social influences on conformity can lead to a better understanding of how a co-witness can influence another person's memory. There are 
two types of influences that can lead to conformity: informational and normative (Deutsch \& Gerard, 1955). Informational influence can lead to conformity when a person is less sure of his or her own belief than what the group or another individual says. In other words, people that conform due to informational influence have a desire to be accurate and believe that the most accurate answer is coming from another person. For example, if two people witnessed a robbery but one had a much better view than the other the witness with the poor view might conform to what the other says because he or she believes the other person has more accurate information.

Unlike informational influence, normative influence leads to conformity because of a person's belief that agreeing with another person will lead to their approval and disagreeing could lead to social rejection or ridicule. People who conform through normative influence might not believe that the other person's information is accurate, but conform simply to go along with the group and avoid the disapproval of others (Deutsch \& Gerard, 1955). A set of experiments by Asch (1951) showed that social influence could cause people to conform with the wrong answer, even when the correct answer is evident. In one of his experiments Asch had the participant in a room with six other people, who were all confederates. The group was shown a standard line and then shown three comparison lines and asked which of the comparison lines matched the first that was shown. When participants answered these types of questions alone they matched the lines correctly about $99 \%$ of the time. When the participant responded to the question in a group, following five confederates who gave the same incorrect answer aloud, about $75 \%$ of all participants conformed to the group's incorrect answer at least once. Normative influence is most likely what led to the instances of conformity because the 
group all identified the same incorrect answer, and the participant most likely conformed to avoid disapproval even though he or she may have known the group's answer was incorrect.

Important variables affecting social influence that were absent from the Asch (1951) studies were task importance and task difficulty. For example, perhaps if Asch rewarded or penalized participants for the accuracy of their answers a different pattern of results would have been found. Baron, Vandello, and Brunsman (1996) conducted two studies to examine these issues. In these studies task importance was manipulated through offering financial and psychological incentives for accurate responses. Study one revealed that tasks with low difficulty and increased task importance resulted in lower conformity than on difficult tasks with increased task importance. Although the low-difficulty-increased-task-importance group did result in less conformity, there was still a significant amount present that differed from the accuracy rates of individuals who performed the task alone. In other words, conformity effects were still observed even when task importance was increased and difficulty was low. Study two more closely examined the finding that increased task importance on a difficult task lead to more conformity. The authors concluded that people conformed more on the high difficulty task because the correct answer could not be easily verified. So, with increased task importance and more uncertainty as to the accuracy of their personal answer, people rely more on the group information about the task. Since the group (made up of confederates) in these experiments strongly supported their choices, conformity with the group increases because the participant sees that the group as a whole is more confident in their answer than their own. In summary, increased task importance can result in less 
conformity on an easy task, but can result in more conformity on a difficult task. These studies also provided evidence that conformity occurred due to both normative and informational influences.

\section{Memory Conformity}

In addition to behavior, social influences can also have an effect on memory conformity. A witness may incorporate PEI into their memory introduced by another person because of social influences. Specifically, a witness's memory may conform to another witness's account as a result of normative influence, informational influence, or a combination of both. Wright, London, and Waechter (2010) developed a model to account for how both normative and informational influences can result in memory conformity (Figure 1). The model proposes that people combine beliefs about their memory with belief in another's memory, which then influences the probability of how they will respond. The belief in memory portion of the model is where informational influences take place, because if the person believes the other person's memory is more accurate that will influence their final response.

Additionally, a person also considers the cost of making an error and the cost of disagreeing. This is where normative influences on conformity occur. After examination of the cost of disagreeing with the other person and the cost of making an error, the person will then ultimately choose the response with the highest expected utility. For example, if the cost of making an error is low and the cost of disagreeing is high then the response with the highest utility for that specific situation would be to agree with the group and maintain their approval. Numerous experiments have examined various normative and informational factors that influence memory conformity with a co-witness. 


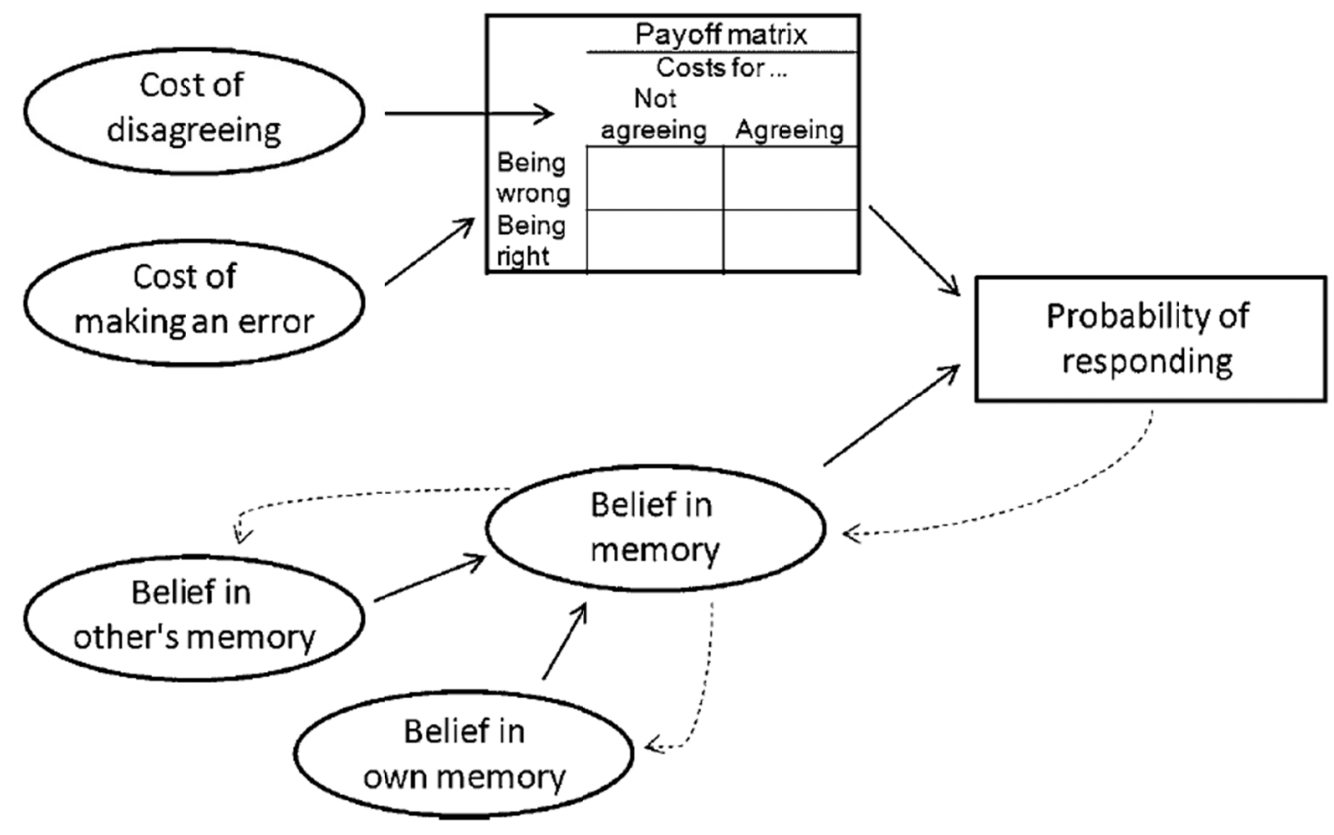

Figure 1. Model of normative and informational influences on memory conformity (Wright, London, \& Waechter, 2010)

Informational Influence on Memory Conformity

Several studies have examined informational influences on memory conformity, through examining such variables as confidence, perceived accuracy, and credibility of the co-witness. Examining confidence, Wright and colleagues (2000) designed an experiment in which pairs of participants were shown an identical crime except that half saw the perpetrator with an accomplice and the other half did not see the accomplice. Participants were given a 16-item questionnaire which contained recognition questions as well as measures of their confidence. This questionnaire was given to the participants immediately after viewing the event and after a collaborative recall session. Although initial memories of the crime were very accurate, most pairs conformed following a discussion of the crime. Who conformed to whom was strongly predicted by confidence 
in one's memory. In other words, the member of the pair who felt less confident in their memory for the crime conformed to the member who was more confident.

Gabbert, Memon, and Wright (2007) conducted an experiment that manipulated perceived accuracy via encoding duration for a set of drawings. Participants who were tested in pairs were told that the other person either had half or twice as long to view each drawing than them, when in reality all participants had equal exposure duration for each drawing. Those who were told that they had viewed the drawings for less time were more likely to conform to what the other person said who supposedly had more encoding time. In other words, participants who conformed believed that the other person's memory was more accurate and so conformed with their memory because they believed that they had the correct answer.

Kwong See, Hoffman, and Wood (2001) manipulated credibility of the source through varying the age of the co-witness. All participants were given a narrative of an event containing four pieces of misinformation and were told that it was received from either a 28 or 82 year old witness. The younger witnesses were rated as more competent than the older witnesses, which was associated with greater misinformation effects. Credibility of the source of information is yet another example of informational influences on memory conformity, with the more credible or competent source yielding greater conformity.

Normative Influence on Memory Conformity

Studies have also found that normative influences can produce memory conformity. Skagerberg and Wright (2008) conducted a study that manipulated power roles. Following viewing 50 photographs of faces, each participant in a pair was assigned 
to be either a designer of a restaurant (low-power role) or a judge of the restaurant design (high-power role). After the restaurant task, the pair completed a memory test for the previously seen faces. Results indicated that the low-power role participants were more likely to conform to the high-power role participants' answers than the high-power role participants were to conform to the low-power role participants' answers. One possible explanation for these results is that the low-power role participant did not want to disagree with the high-power role participant and so he or she conformed to escape potential disapproval. The cost of disagreeing may have been perceived as higher than the cost of making an error, resulting in the highest utility response of conforming to the person in the high-power role. Power is a complex concept, and future studies are examining when power roles affect memory conformity (Carol, Carlucci, Eaton, \& Wright, 2011).

Another normative influence that affects memory conformity is social anxiety. Specifically, Wright and colleagues (2010) found that two components of social anxiety (fear of negative evaluation and social avoidance) moderate the effects memory conformity in adolescents. The results indicated that those participants who had a higher level of fear of negative evaluation were more likely to conform to their partner's answers on a memory test. In other words, adolescents who were more fearful of other people evaluating them negatively were more likely to conform to their partner than those adolescents who did not have this fear. This exemplifies normative influences on memory conformity because it shows the importance of the opinion of the other person. Contrary to the fear of negative evaluation results, those with high social anxiety scores (people who avoid social interactions) were less influenced by their partner, and showed 
less memory conformity. So those people who were more fearful of negative evaluations conformed to avoid any disagreement, and those who tend to avoid social situations and are less influenced by others conformed less.

\section{Prior Relationships and Memory Conformity}

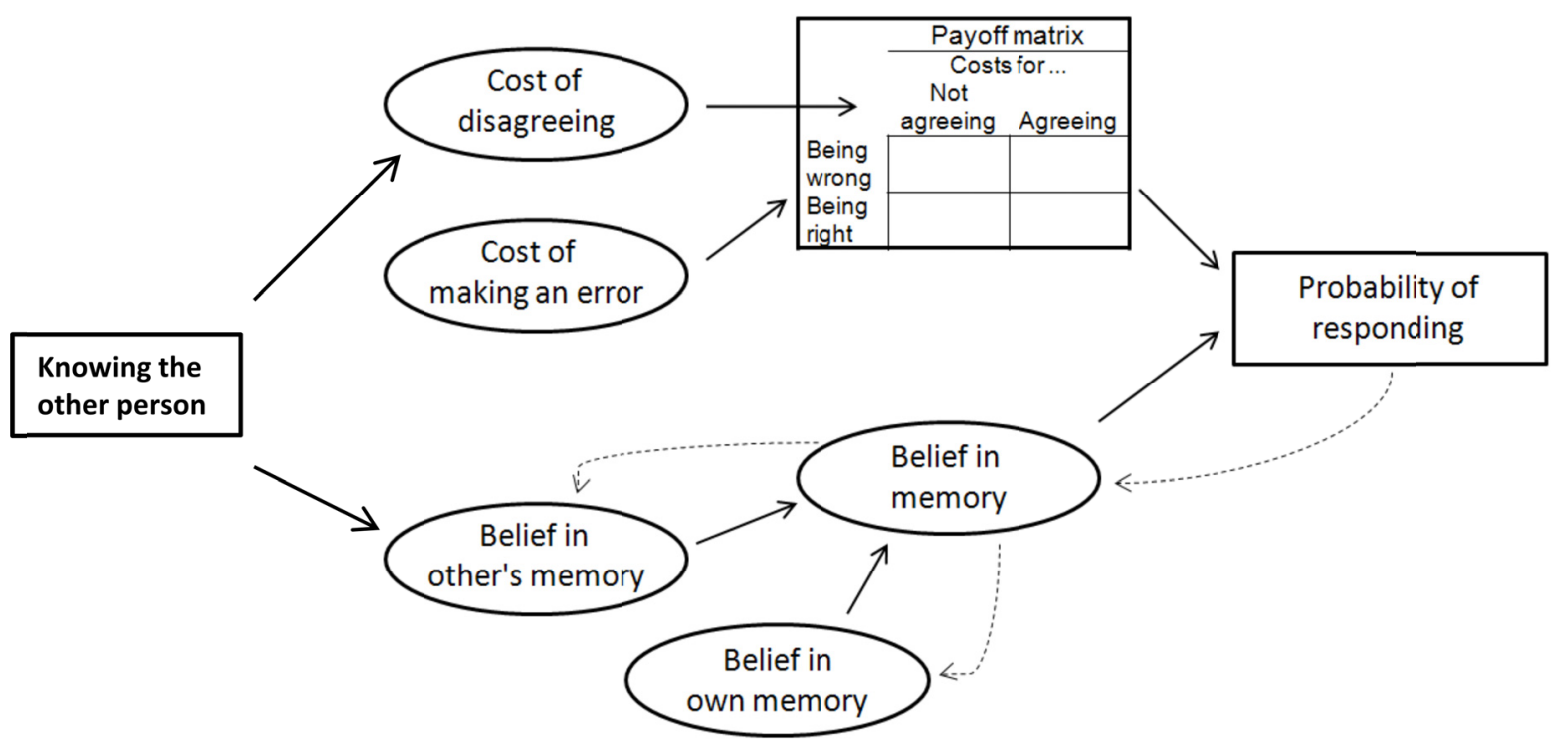

Figure 2. Model of normative and informational influences on memory conformity taking into account prior relationships between co-witnesses.

Another factor that influences memory conformity is the relationship between the people who are remembering. Prior relationships can affect memory conformity via nominal or informational influences, or a combination of both. Presence of a prior relationship may affect memory conformity through normative influences because there may be an elevated cost of disagreeing with someone you know versus disagreeing with a stranger. The increased cost of disagreement between those with a previous relationship can lead to more memory conformity, to avoid the disagreement altogether, depending on the cost of making an error (Figure 2). This may also be true for people who do not have as strong of a prior relationship, such as people who recently met, but still may conform 
to the other person to avoid a disagreement or negative evaluation from the other person. Additionally, when two people are already friends or romantically involved liking and social bonds are present, which can influence how they converse with one another and ultimately how they remember.

Prior relationships can also affect memory conformity through informational influences. In other words, the knowledge one has about the other person, such as their memory abilities or memories of shared events, can influence memory conformity (Figure 2). Researchers have suggested that friends and couples develop transactive memory systems, meaning that each has insight into the other's way of thinking which can allow for increased sharing of an individual's knowledge (Wegner, 1986; Wegner, Erber, \& Raymond, 1991). Likewise research has shown that those with previous relationships outperform strangers in paired recall tasks because of increased cue effectiveness and mutual cueing (Andersson, 2001; Andersson \& Rönnberg, 1995, 1997; Fussell \& Krauss, 1989). Although remembering a shared event can be beneficial, when incorrect information is introduced these same advantages can turn into disadvantages and over-reliance on this other person may result in the witness providing inaccurate information.

French and colleagues (2008) conducted a study in which pairs of romantic partners and strangers witnessed an event and then discussed their memories with the other person. The event viewed was slightly different for each member of the pair. This meant that some of the memories for the event discussed by one of the pair would not have been viewed by the other. For those memories that were discussed, at recall some participants incorrectly reported information from their partner's discussion. Those who 
discussed the event with their romantic partner were more likely to report false memories (memories that they did not experience themselves) than those who discussed the event with a stranger. The authors suggested that the pairs of romantic partners were more likely to incorporate their partner's memories due to informational influences, meaning that they thought their partner's memory was more accurate and reliable than their own. While romantic partner pairs showed no signs of normative influences, stranger pairs produced a pattern that suggested normative influence $25 \%$ of the time. In other words, individuals who were part of a stranger pair changed their original answers from the group test during the individual memory test $25 \%$ of the time, which indicates that the stranger pairs conformed to their partner's answers $25 \%$ of the time for normative reasons. Since romantic partners did not show the same pattern of results the authors concluded the romantic partner pairs must have believed their partner's answer to be correct, and so did not change it on the individual memory test.

Hope and colleagues (2008) conducted a study examining susceptibility to misinformation among individuals and pairs of romantic partners, friends, and strangers. Participants began the study by each viewing a crime video. If the participants were in a pair each member saw a slightly different perspective of the crime. Following viewing the video and a short filler task the participants either entered into the memory rehearsal phase (individual) or memory discussion phase (strangers, friends, and romantic partners), where PEI may have been introduced. PEI was not introduced to those that participated individually. The authors found that the pairs were more susceptible to misinformation and produced less accurate recall than individuals. Pairs that were previously acquainted, including both romantic couples and friends, were significantly 
more likely to report misinformation from their partner that they had not seen themselves than strangers. One possible explanation for why those who are previously acquainted were more likely to conform to their partner's memory is source credibility. Perhaps having a prior relationship with the co-witness gives them knowledge of their competence, which may affect memory conformity more than if the two were strangers. For example, if one friend knew the other was a credible source it could lead to more memory conformity. Alternatively, if one friend knew that the other person was not a credible source, and perhaps had a bad memory, it could lead to less memory conformity. Another explanation of how prior relationships can affect memory conformity is the degree of identification felt with the source of information (Walker \& Heyns, 1962). The degree of identification, or liking, that one individual feels with the co-witness may determine the level of conformity. In both the Hope et al. (2008) and French et al. (2008) studies the results found for the friends and romantic partners may be explained by their increased sense of identification or liking with the other. So the larger magnitude of liking that exists between friends and romantic partners over the magnitude of liking found between strangers may explain the higher levels of memory conformity.

Along with the presence of a previous relationship also brings in other factors that may influence conformity, like knowledge of the other's memory abilities and how the other person thinks. Since these other factors are also present, likability's effect on memory conformity needs further examination. Hope et al. (2008), however, found a result that may allow for a more generalized theory of likability and memory conformity. They found that previously unacquainted participants who incorporated misinformation from the co-witness also gave increased liking ratings. These results indicated that 
increased liking may influence memory conformity overall, regardless of previous relationship, however the likability ratings were taken after memory conformity had already occurred, thus confounding the results. Unfortunately that study was not designed to determine whether the likability of the co-witness influenced memory conformity, or whether the participant rated the co-witness more likable because they recalled similar items.

Rapport-building and Memory Accuracy

Rapport-building, another area of research outside from the conformity literature, provides an alternative insight into how liking another person may influence memory conformity and accuracy. Many different definitions exist on how to define rapport, but it can be generally thought of as a "harmonious, sympathetic connection to another" (Newberry \& Stubbs, 1990, p. 14). Rapport-building with interviewees is recommended to investigators by most witness interviewing guidelines to increase witness' recall accuracy. These guidelines include the Cognitive Interview (Fisher \& Geiselman, 1992), Eyewitness Evidence: A Guide for Law Enforcement in the United States (Technical Working Group: Eyewitness Evidence, 1999), as well as A Guide to Interviewing (CPTU, 1992a) and The Interviewer's Rule Book (CPTU, 1992b) in the United Kingdom as part of the PEACE model of investigative interviewing. Thus these interviewing guidelines suggest that rapport increases accuracy, in part, through developing liking on the part of the interviewee towards the interviewer. Studies have found that rapport-building increases the quality of witness statements through increasing their accuracies (Collins, Lincoln \& Frank, 2002) or through decreasing their inaccuracies when presented with incorrect PEI (Vallano \& Schreiber Compo, in press; Kieckhaefer, Vallano \& Schreiber 
Compo, 2011). In summary, liking the other person may not increase memory conformity but instead may increase memory accuracy.

\section{Current Study}

The current study examined this specific, previously unexplored, area to see whether manipulating liking itself, without any other elements of friendship, has any influence on memory conformity and memory accuracy. The empirical question has great theoretical importance because it will allow for a more in depth examination of what role 'liking' has in memory conformity and memory accuracy. Since likability has been shown to increase both memory conformity and memory accuracy it is important to better understand the mechanisms involved. The current study also has practical importance because it will examine what happens when two people who were previously strangers have built liking for one another. Insight into whether these people are likely to conform to the other's memory on the basis of whether the participant likes the cowitness or not could be useful information for police officers when they interview witnesses of a crime. If liking is found to increase memory accuracy than this study would give further support to the use of rapport-building with eyewitnesses.

\section{Hypotheses}

Research Question 1: Is there a significant difference in memory conformity effects among the control and likable conditions?

Since the literature on memory conformity and rapport-building present two possible opposing explanations, the results may either show an increase in memory conformity or a decrease in memory conformity, due to an increase in memory accuracy.

On the one hand, if the results support the previous memory conformity findings there 
will be a significant increase in memory conformity effects between those who like the other person and those who receive no liking manipulation (control group). In other words, if the participant likes the other person then they will be more likely to agree with the other person's statement (which may be correct or incorrect) than if liking is not built between them. This is in accordance with the finding that previously unacquainted participants who incorporated misinformation from the other person also gave increased liking ratings (Hope et al., 2008). This result would also support the increased degree of identification hypothesis, whereby those that feel a higher degree of identification, or liking, are more likely to conform (Walker \& Heyns, 1962).

On the other hand, if the results support the rapport-building literature, the amount of memory conformity for those in the likable condition will be significantly less than the level of memory conformity in the control condition. Since rapport-building has been found to increase statement quality (Collins et al., 2002; Vallano \& Schreiber Compo, in press; Kieckhaefer et al., 2011), building likability between two unacquainted individuals should increase memory accuracy, which would decrease memory conformity.

Research Question 2: Is there a significant difference in memory conformity effects among the control and dislikable conditions?

Since no prior research has examined dislikability's effects on memory conformity, there are three possible outcomes. The first potential result is that memory conformity will decrease from the control to the dislike conditions. This result may indicate that participants in the dislike condition respond in the opposite way as the other person, possibly because they think less of them or may not want to agree due to their 
dislike of him/her. This result would be in accordance with the degree of identification hypothesis (Walker \& Heyns, 1962). Since those in the dislikable condition would feel less identification with the other person they would be less likely to be influenced by memory conformity.

The second potential result is that memory conformity for the dislike condition will not differ significantly from the control group. This would indicate that the participants in the dislike condition ignored the other person as a source of information when stating their own answers.

The third possible result is that memory conformity for those in the dislikable condition will increase from the control condition. This result would indicate that the participant is agreeing more with what the dislikable person answered than with someone who he/she did not build disliking. This result would be supported by the normative influence literature, whereby participants conform to avoid the disapproval of others or in an uncomfortable social situation (Deutsch \& Gerard, 1955). Fear of negative evaluation could also explain this result, meaning that participants may have an increased fear of negative evaluation (since the other person is acting dislikable towards them) and so they are more likely to conform in an effort to not be negatively evaluated (Wright et al., 2010). 


\section{Chapter II \\ METHODOLOGY}

Design

The study used a 3 between subjects (likability: control vs. liking vs. disliking) by 2 within subject (confederate response to photograph: old vs. new) by 2 within subject (accurate response to photograph: old vs. new) mixed factorial design. The outcome variable was whether the participant reported having seen the stimulus before.

\section{Participants}

One hundred and thirty undergraduate participants from Florida International University’s Psychology department were recruited through SONA Systems. Each participant was given one credit of research participation, which could be used towards extra credit in an undergraduate psychology course. Students were randomly assigned to an experimental condition before arriving at the research laboratory. A power analysis was conducted using GPower software 3 (Faul, Erdfelder, Lang, \& Buchner, 2007). The results of the analysis indicated that the sample size should be at least 99 total participants to achieve an alpha $=.05$, and power $=.90$ for detecting $\eta^{2}=.15$.

Of the 130 participants who completed this study, the data from 127 are included in the final sample. The data for two participants were excluded because they guessed the research confederate part of the study. One participant was excluded because he/she did not follow the experimenter's instructions. Of the final sample, a majority of participants were female $(65.4 \% ; 34.6 \%$ male), and Hispanic $(74.0 \% ; 8.7 \%$ Caucasian; 7.1\% African American; 5.5\% Asian; 4.7\% Other). The average age of participants was $M=20.81(S D=3.68)$ years. 


\section{Procedure}

Upon arriving to the laboratory all participants were asked to read and to sign an informed consent form (Appendix A). Another student was also present who the participant thought was also completing the study for extra credit when in actuality the person was a confederate. Participants were told the experiment was about determining friendship compatibility with another student and that their first task was for one of them to interview the other. To determine who was interviewed a random selection procedure was simulated in which the research assistant assigned numbers, either " 1 " or " 2 ," to each student. The research assistant explained that whoever drew the number 1 was going to be interviewed and whoever drew the number 2 was going to interview the other person. The actual participant was then asked to pull a sheet of paper from a cup, all of which had the number " 1 " written on one side. The number " 1 " was assigned to the participant and the number " 2 " was always be assigned to the confederate. A sheet of interview questions, containing fifteen small group icebreaker questions, was then given to the confederate who interviewed the participant (Grahame, 2008; Appendix B). Examples of the types of questions that were asked include "What's your favorite thing to do in the summer?" and "If you could learn any skill what would it be?" The confederate was instructed to write down the participant's response. Likability was manipulated during the interview of the participant. Each of the four research confederates were trained for five hours on how to act during each experimental condition. All confederates were assessed on their knowledge and acting abilities for all conditions prior to their assistance in the study. 
Liking. In the liking condition the confederate gave eye contact, smiled, and engaged in active listening. In addition to these nonverbal behaviors, the confederate also wrote many words on the interview response paper to describe the participant's answer. The confederate did not agree with the participant's answers, to avoid a potential confounding effect with similarity of responses and likability. Instead, the confederate responded in a positive manner, asking about the answer or giving some positive reinforcement. For example, if the participant stated their favorite television show the confederate would respond saying that she had not seen that show but have heard great things about it and would like to see it in the future. The confederate thus created a positive environment in which the participant felt listened to and understood.

Disliking. In the disliking condition the confederate did not look at the participant, did not smile, did not engage in active listening, and wrote only a couple words to summarize the participant's answers. The confederate spoke to the participant in a monotonous tone of voice. Also, the confederate responded to the participant's statements in a negative manner. For example if the participant stated their favorite television show the confederate responded by saying, "well it can't be that great if I haven't heard of it." Disagreements with the participant were avoided, just as with agreements, to avoid any possible confounding effects with similarity and likability. The confederate thus created a negative environment through responding negatively to the participant's answers, pretending not to listen or be distracted, and generally gave the participant the feeling that the confederate did not like or care about the participant. A more direct manipulation of liking and disliking was considered, however the current manipulation was felt to be best because of potential ethical limitations. 
After the interview was complete the research assistant took the papers from the confederate. The research assistant then explained that each of them will fill out a compatibility questionnaire about the other person and then handed each a form (Appendix C).

Control. If the participant was in the control condition the research assistant explained that the study was looking at compatibility among students. The research assistant further explained that they were attempting to compile a database of what Florida International University students are like, and that they will be writing answers about themselves on a sheet of paper. The research assistant then handed an interview sheet to the participant and one to the confederate, who each filled out the sheets independently from one another without conversation (Appendix B). No interaction occurred between the participant and confederate in this condition. Following their completion of the interview sheet the research assistant then provided each of them with a compatibility questionnaire to fill out about the other person (Appendix C). Each filled out a compatibility questionnaire about the other even though they did not interact.

Presentation of stimuli. Each participant-confederate pair was presented 50 images of houses on a computer screen using PowerPoint (Appendix D). Houses were chosen as the stimuli material both for their applied value (i.e., remembering the house where you left your children) and because they are complex stimuli. These images were viewed for 5 seconds each on a computer screen. The order of image presentation was random. Following the presentation of the 50 images the participant and confederate independently completed a five minute word completion filler task (Appendix E). 
Social recognition test. Participants' memories were tested using the social recognition test (SRT) procedure for the 50 images that were previously seen and 50 new images (Schneider \& Watkins, 1996; Wright, Mathews \& Skagerberg, 2005; Wright \& Schwartz, 2010). The SRT has been used in several memory conformity studies be it allows for the collection of a large amount of data per participant. This procedure was also advantageous because it introduced PEI from another person through controlled social interaction. For example, in the current study the confederate and participant were shown 100 images during this testing phase, 50 previously seen photos and 50 new photos that were similar to those previously viewed. The confederate was told to answer first since the participant was the one who was interviewed earlier in the study. When the photos were presented on a computer screen the confederate indicated whether the photo was old or new on an answer sheet. These responses were either correct (saying old to old photo or new to new photo) or incorrect (saying old to new photo or saying new to old photo). The confederate's responses and the participant's were said aloud so that the research assistant could record their answers (Appendix F). This procedure ensured that the participant received PEI through hearing the confederate's response.

Immediately following the SRT procedure the participants were asked if they observed anything strange during the study and what they thought the study was about. These questions were asked to gauge whether the participant knew the other person was a confederate. After these questions were asked, the participants were told that the other student was actually a confederate. The research assistant then asked the participant if they suspected the confederate at any point during the study, and if so when and why. The participant was then asked to fill out a demographics questionnaire (Appendix G). 
Lastly, participants were debriefed about the purpose of the study and thanked for their participation (Appendix H). 


\section{Chapter III}

\section{RESULTS}

\section{Pilot Tests of Stimulus Materials}

The photographic stimulus materials and the length of time they were presented were pilot tested for accuracy with 29 individuals (see Table 1). The desired accuracy rate for the 100 photos was above $50 \%$, to ensure they were more accurate than chance. The first test of the materials consisted of each of the 50 stimulus photos being presented for 3 seconds. At the test, they were shown the same 50 photos and 50 new pictures in a random order. This condition yielded a mean accuracy rate of $54.75 \%$. In an attempt to increase the participants' accuracy the duration that each photograph was shown was increased to 5 seconds, which resulted in an accuracy rate of $63.22 \%$. In response to some participant comments that the photographs all looked very similar, 20 of the 100 photos were replaced with more distinctive photos. The participants in this condition had a recall accuracy rate of $64.31 \%$. Once the desired accuracy rate of an individual taking this memory test was achieved, the pilot testing ended.

Table 1. Accuracy of Memory for House Photographs (in percentages)

\begin{tabular}{lccccc} 
Condition & Accuracy & $\begin{array}{c}\text { Says old, } \\
\text { is old } \\
\text { (Hit) }\end{array}$ & $\begin{array}{c}\text { Says old, is } \\
\text { new } \\
\text { (False alarm) }\end{array}$ & $\begin{array}{c}\text { Says new, } \\
\text { is old } \\
\text { (Miss) }\end{array}$ & $\begin{array}{c}\text { Says new, is } \\
\text { new } \\
\text { (Correct Rejection) }\end{array}$ \\
\hline $\begin{array}{l}3 \text { seconds } \\
(\mathrm{N}=4)\end{array}$ & 54.75 & 26.25 & 23.50 & 21.50 & 28.75 \\
$\begin{array}{l}5 \text { seconds } \\
(\mathrm{N}=9)\end{array}$ & 63.22 & 30.67 & 19.33 & 17.44 & 32.56 \\
$\begin{array}{l}5 \text { seconds, } \\
\text { new pics } \\
(\mathrm{N}=16)\end{array}$ & 64.31 & 29.13 & 20.88 & 14.81 & 35.19 \\
\hline
\end{tabular}




\section{Preliminary Analyses}

Confederate Effects. Multivariate analyses of variance (MANOVAs) were conducted on items measuring likability within the compatibility questionnaire to examine whether the different confederates or research assistants affected participants' ratings of likability. There was no effect of confederate on participants' ratings of likability $F(42,336)=1.05, p=.39$, nor any research assistant effect on participants' ratings of likability, $F(56,448)=1.17, p=.19$, independent of likability condition. Any differences between likability conditions are thus unlikely to be the result of the specific confederates or research assistants.

Likability Manipulation Check. In order to see whether participants perceived the three levels of likability for the confederate differently the compatibility questionnaire was examined and served as a manipulation check. A series of one way ANOVAs examining likability condition (control v. likable v. dislikable) for the fourteen compatibility questions showed that likability condition significantly affected participants' perceptions of the confederate overall (Table 2). All of the fourteen compatibility questionnaire measures showed significant differences among conditions $(p<.001)$. All measures also followed the appropriate pattern of results. The likability condition received the highest ratings on the positive items and the lowest ratings on the negative items. Likewise, the dislikable condition received the lowest ratings on the positive items and the highest ratings on the negative items. The control condition's ratings fell between the likable and dislikable ratings. Follow-up comparisons revealed that six of the measures (awkward, involved, positive, cold, perceptive, and general impression of the other person) were significantly different from the other in each 
condition. Eight of the measures (inattentive, bored, friendly, trustworthy, incompetent, similar, rating of the other person, and how you think your partner will evaluate you) were only significantly different in the likable condition. In other words, the likable condition was significantly different from the control and dislikable conditions, however the dislikable and control conditions were not significantly different from each other for those eight measures.

Table 2. Likability Manipulation Check

\begin{tabular}{lcccccccc} 
& \multicolumn{2}{c}{$\begin{array}{c}\text { Control } \\
(\mathrm{N}=40)\end{array}$} & \multicolumn{2}{c}{$\begin{array}{c}\text { Likable } \\
(\mathrm{N}=44)\end{array}$} & $\begin{array}{c}\text { Dislikable } \\
(\mathrm{N}=43)\end{array}$ & & \\
\cline { 2 - 9 } & $M=$ & $S D=$ & $M=$ & $S D=$ & $M=$ & $S D=$ & $p$ & $\begin{array}{c}\text { Partial } \\
\eta^{2}\end{array}$ \\
\cline { 2 - 9 } & & & & & & & & \\
Awkward*** & 2.13 & 1.09 & 1.57 & 0.90 & 3.12 & 1.30 & $<.001$ & .26 \\
Involved*** & 3.40 & 1.30 & 4.48 & 1.32 & 2.67 & 1.09 & $<.001$ & .27 \\
Positive*** & 3.50 & 1.18 & 4.68 & 1.18 & 2.70 & 0.99 & $<.001$ & .35 \\
Cold*** & 2.50 & 1.32 & 1.36 & 0.69 & 3.21 & 1.47 & $<.001$ & .30 \\
Perceptive*** & 3.50 & 0.99 & 4.27 & 1.04 & 2.84 & 1.18 & $<.001$ & .25 \\
Gen. Impression*** & 4.13 & 0.94 & 5.41 & 0.87 & 3.44 & 1.08 & $<.001$ & .43 \\
Inattentive** & 3.22 & 1.58 & 1.70 & 1.41 & 3.42 & 1.66 & $<.001$ & .22 \\
Bored** & 3.73 & 1.41 & 2.05 & 1.35 & 4.33 & 1.57 & $<.001$ & .32 \\
Friendly** & 3.18 & 1.15 & 5.00 & 1.28 & 2.79 & 1.17 & $<.001$ & .40 \\
Trustworthy** & 2.83 & 1.04 & 3.86 & 1.15 & 2.88 & 1.04 & $<.001$ & .17 \\
Incompetent** & 2.08 & 1.21 & 1.32 & 0.93 & 2.35 & 1.31 & $<.001$ & .13 \\
Similar** & 2.40 & 0.93 & 3.95 & 1.10 & 2.23 & 1.17 & $<.001$ & .35 \\
Rating of Other** & 3.82 & 0.87 & 5.23 & 0.91 & 3.42 & 1.18 & $<.001$ & .38 \\
Partner Eval. You** & 3.60 & 1.24 & 4.57 & .93 & 3.26 & 1.50 & $<.001$ & .19 \\
\hline
\end{tabular}

\footnotetext{
*** All groups (control, likable, and dislikable) significantly different from each other, $\mathrm{p}<.05$

** Likable significantly different from control and dislikable groups, but control and dislikable do not significantly differ

\section{Primary Analyses}

The likability manipulation resulted in significant differences among the conditions in memory accuracy. Participants were more likely to be accurate (saying old when picture was old, and saying new when picture was new) when in the likable
} 
condition $(65.09 \%)$ than in the dislikable condition (61.88\%). In Figure 3 the memory accuracy effect can be seen through examining the "is old, confederate says old" condition. The likable condition had the lowest percentage of "new" responses, indicating that they were the most accurate because the correct response was "old." The memory accuracy effect can also be seen through examining the "is new, confederate says old" condition. In this condition the likable condition had the highest percentage of correct "new" responses compared to the other two groups, indicating that those in the likable condition were most accurate.

The likability manipulation also resulted in significant differences among conditions in memory conformity. Participants were more likely to conform when in the dislikable condition (58.78\%) than in the likable condition (56.27\%). This memory conformity effect can also be seen in Figure 3 through examining the differences in the "new" response percentages depending on what the confederate said. For example, when the picture was old the participants' responses in the dislikable condition changed $16.74 \%$ from when the confederate said "old" compared to when the confederate said "new" while the likable condition participants' responses only changed $13.09 \%$. When the picture was new the participants' responses in the dislikable condition changed $18.50 \%$ from when the confederate said "old" compared to when the confederate said "new" while the likable condition participants' responses only changed $11.19 \%$. The larger changes in the percentage of "new" responses in the dislikable condition are consistent with participants in the dislikable condition being more likely to conform to the confederate than those in the likable condition. 


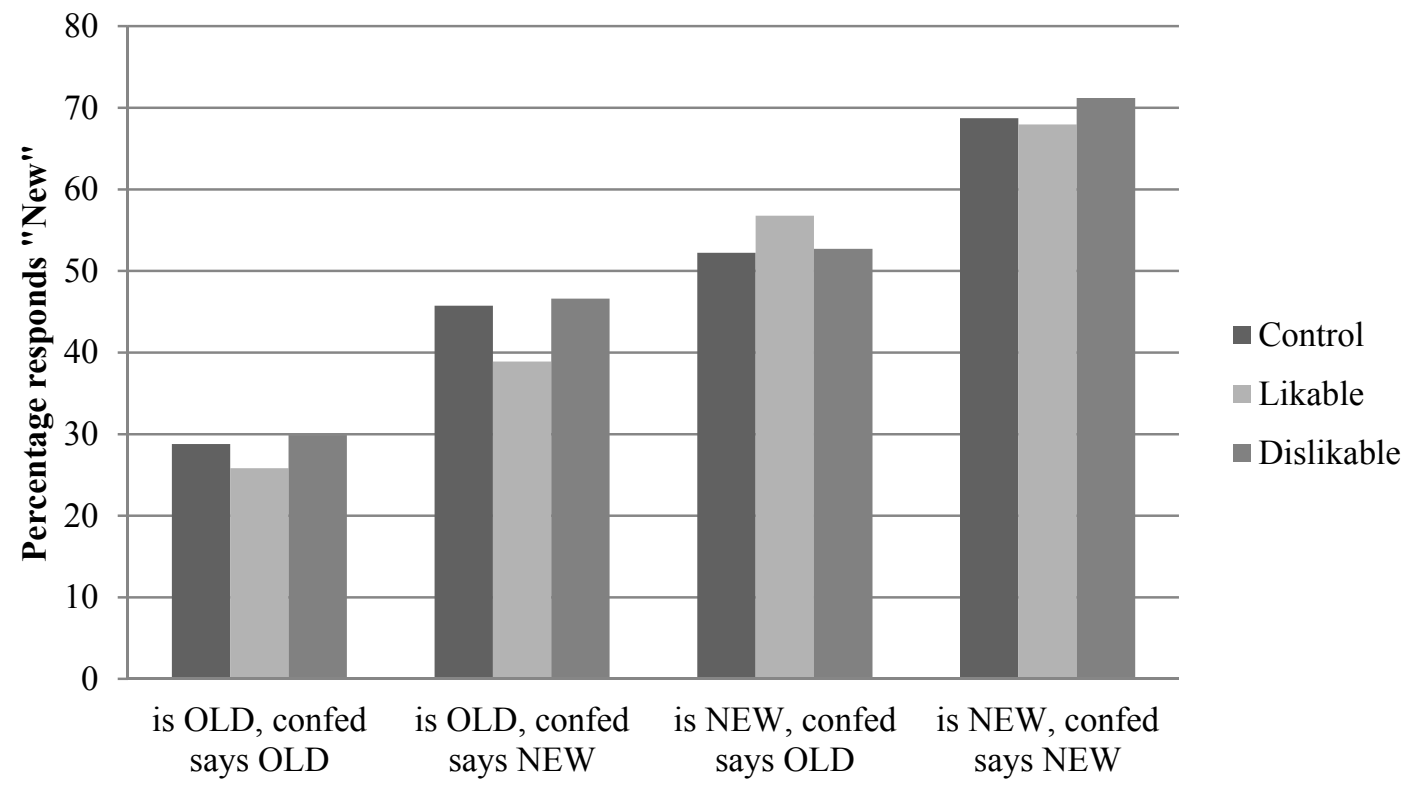

Figure 3. Memory and memory conformity effects: The percentage of the participant saying "new" in four accuracy-confederate response conditions.

To support these general findings, and since the response each participant gave in the SRT was binary (old or new), a multilevel logistic regression was used to analyze the data. This analysis involved predicting the participant's response from the type of photo that particular item was (either old or new) and how the confederate responded to that same item (Wright \& Schwartz, 2010). The effect of memory conformity can be measured by finding the best fit for the following model (to the right of the $\sim$ ):

\begin{tabular}{|c|c|c|}
\hline Probability participant reports "new" $\sim \beta 0$ & $\begin{array}{l}+\beta 1 \\
+\beta 2 \\
+\beta 3(\mathrm{a}) \\
+\beta 3(\mathrm{~b}) \\
+\beta 4(\mathrm{a}) \\
+\beta 4(\mathrm{~b}) \\
+\beta 5(\mathrm{a}) \\
+\beta 5(\mathrm{~b})\end{array}$ & $\begin{array}{l}\text { Whether picture is new (is) } \\
\text { What the confederate said } \\
\text { Likable condition } \\
\text { Dislikable condition } \\
\text { Interaction between likable } \\
\text { condition and confederate } \\
\text { Interaction between dislikable } \\
\text { condition and confederate } \\
\text { Interaction between likable } \\
\text { condition and is } \\
\text { Interaction between dislikable } \\
\text { condition and is }\end{array}$ \\
\hline
\end{tabular}


The regression model was built in three steps, shown in Table 3. In the first step (shown as Model 1), whether the photo was new, what the confederate said, and the likability condition were entered as predictors of when the participant said "new". Participants were more likely to correctly say "new" if the photograph was new than if it was old $(p<.001)$. Participants were also more likely to say "new" if the confederate also said "new" than if the confederate said "old" $(p<.001)$. This shows that there was both memory accuracy and memory conformity.

In the second step of the model, the interaction between likability condition and what the confederate said was added. This interaction was a significant predictor, $\chi^{2}(2)=7.72, p=.02$. This shows that the size of the conformity effect was moderated by the likability condition the participant was in. The parameter estimate indicates that there was significantly less conformity in the likable condition than in the control condition, $\beta 4(\mathrm{a})=-.20, \mathrm{SE}=.10, p=.04$. The dislikable condition and the control condition were not significantly different.

Table 3. Comparison of Regression Models Predicting Accuracy from Whether the Picture is New, the Confederate's Response, and Likability Condition

\begin{tabular}{|c|c|c|c|c|c|c|c|c|c|}
\hline & \multicolumn{3}{|c|}{ Model1 } & \multicolumn{3}{|c|}{ Model2 } & \multicolumn{3}{|c|}{ Model3 } \\
\hline & Est & $S E$ & $p$ & Est & $S E$ & $p$ & Est & $S E$ & $p$ \\
\hline \multicolumn{10}{|l|}{ Fixed effects } \\
\hline Intercept & -0.99 & 0.14 & $<.001$ & -1.02 & 0.14 & $<.001$ & -0.95 & 0.14 & $<.001$ \\
\hline Is new (accuracy) & 1.22 & 0.13 & $<.001$ & 1.22 & 0.13 & $<.001$ & 1.09 & 0.14 & $<.001$ \\
\hline Confed says (mem conf) & 0.67 & 0.12 & $<.001$ & 0.73 & 0.13 & $<.001$ & 0.72 & 0.13 & $<.001$ \\
\hline Cond(Like) & -0.08 & 0.12 & 0.51 & 0.02 & 0.13 & 0.86 & -0.16 & 0.14 & 0.27 \\
\hline Cond(Dislike) & 0.06 & 0.12 & 0.62 & 0.04 & 0.13 & 0.78 & 0.02 & 0.14 & 0.90 \\
\hline Cond(Like) x Confed & & & & -0.20 & 0.10 & 0.04 & -0.18 & 0.10 & 0.06 \\
\hline Cond(Dislike) x Confed & & & & 0.05 & 0.10 & 0.62 & 0.05 & 0.10 & 0.61 \\
\hline Cond(Like) x Is new & & & & & & & 0.34 & 0.10 & $<.001$ \\
\hline \multirow[t]{2}{*}{ Cond(Dislike) x Is new } & & & & & & & 0.04 & 0.10 & 0.71 \\
\hline & & & & \multicolumn{3}{|c|}{$\begin{array}{l}\text { Model1 v. Model2 } \\
\chi^{2}(2)=7.72, p=0.02\end{array}$} & \multicolumn{3}{|c|}{$\begin{array}{c}\text { Model2 v. Model3 } \\
\chi^{2}(2)=14.98, p<.001\end{array}$} \\
\hline
\end{tabular}


In the third step of the model, the interaction between likability condition and whether the picture was new was entered. This interaction was a significant predictor, $\chi^{2}(2)=14.98, p<.001$. Those in the likable condition were more accurate than those in the control condition, $\beta 5(\mathrm{a})=.39, \mathrm{SE}=.10, p<.001$. This difference between the dislikable condition and the control condition was not significant. 


\section{Chapter IV}

\section{DISCUSSION}

\section{Likability and Memory}

The aim of the current study was to examine whether likability built between two co-witnesses plays a role in both memory accuracy and memory conformity. Results from this experiment show that likability did have a significant positive effect on witness accuracy. Overall, participants in the likable condition were more accurate than those in the dislikable condition (65.09\% vs. $61.88 \%)$. Accuracy in the likability condition was a significant predictor as to whether or not the participant answered "new" to previously unseen items compared with participants in the control condition.

The finding that likability improved accuracy supports prior research showing that rapport-building, or creating a comfortable and cooperative relationship, increased witness accuracy (Collins et al., 2002; Vallano \& Schreiber Compo, in press; Kieckhaefer, et al., 2011). Perhaps those in the likable condition were not as concerned about their partner's opinion of them as those in the dislikable condition, and thus were more able to attend to their own memory for each picture. It is also possible that through building likability the participant's accuracy was increased by reducing their anxiety, which has been supported in the child eyewitness rapport-building literature (Almerigogna, Ost, Bull, \& Akehurst, 2007; Quas \& Lench, 2007). Building liking between two people is an easy and effective way to significantly increase accuracy of memory in this group of students. In other words, being nice to people does seem to make a positive difference in memory accuracy. 
Another goal of this study was to determine whether the nature of likability increased the susceptibility to misinformation from the co-witness. Results show that dislikability was associated with more memory conformity. Those in the dislikable condition were significantly more likely to conform to the confederate's responses than those in the likable condition. For instance, those in the dislikable condition's answers changed more in accordance with the confederate's response than the likable condition $(18.50 \%$ vs. $11.19 \%)$. Although changes in responses in accordance with the confederate's answers were evident in both the likable and dislikable conditions, the dislikable condition had a significantly greater amount of memory conformity.

The fact that dislikability increased the memory conformity effect is in accordance with the normative influence literature. These findings indicated that those in the dislikable condition may have conformed more to the confederate's responses to avoid any subsequent disapproval from the confederate, or in an effort to make the situation less uncomfortable (Deutsch \& Gerard, 1955). Although the evaluations of one another occurred before the memory test (during the compatibility questionnaire), the participants in the dislikable condition could have conformed more to the confederate due to fear of continued negative evaluations (Wright et al., 2010). In other words, the participants in the dislikable condition may have conformed more in an effort to change the confederate's rating of them because they felt they were rated poorly before and/or will be rated poorly in the future.

\section{Practical Implications}

The results of this study have several implications for the real world for both memory accuracy and memory conformity. One implication this research has is that it 
does matter what co-witnesses think of each other. This should be an area for eyewitness researchers to conduct further research to look at the different ways in which dyads interact. Another possible implication of this study, along with further research conducted to support its claims, are policy implications for the criminal justice system. Such policy implications might include the investigator noting the relationship between the witnesses along with their perceived likability for each other, which could be used later when examining their witness statements.

Another important practical implication of this study is that being likable may increase memory accuracy in a variety of situations, including therapeutic settings and while conducting interviews. Although the rapport-building literature has supported this general finding for years, the current study contributed an understanding of what happens when a person is viewed as dislikable. The current study's findings show that acting dislikable should be avoided in all situations in order to limit memory conformity and increase memory accuracy.

\section{Limitations and Future Directions}

One limitation of this research concerns the type of event that was used in this study and how that can be translated into a real world situation. Although the social recognition test procedure is very effective in producing large amounts of data, viewing 50 pictures of houses followed by being tested on 100 pictures of houses is not representative of most eyewitness situations. Future studies should examine the effects of likability in different contexts, like witnessing and describing an event, to ensure that the effect is not specific to pictorial stimuli. 
Another limitation with the current study is that the participant and confederate were tested together. Interviewing protocols suggest that police officers interview witnesses separately, whereas in this experiment the two were sitting across the table from each other. Future research should examine whether the effects of likability continue after the other person is out of the immediate situation. Research on rapportbuilding would suggest that the effects of likability may last longer than the current study, however there is no information on the length of the effect of the dislikable condition. Perhaps in the dislikable condition the influence is normative, and once the other person is out of sight the increased memory conformity effects will dissipate since the other person is no longer present creating an uncomfortable situation.

Another potential limitation of this research is that it used an undergraduate student sample. Questions can be raised as to whether or not the effects of likability on memory accuracy and conformity can generalize to other important populations, such as uncooperative witnesses and different populations such as children and the elderly. It would be interesting to manipulate likability and dislikability with a sample of children to see if the same results of memory accuracy and conformity would be replicated.

\section{Conclusion}

This study examined the effects of likability and dislikability on memory accuracy and memory conformity. Results indicated that building liking between two previously unacquainted individuals significantly increased accuracy on a memory test of images. The presence of such a positive memory accuracy effect is promising, considering the stimuli were photographs and not an event. Furthermore, results also showed that building dislikability between two previously unacquainted individuals 
significantly increased the amount of memory conformity. This experiment and its results are novel and important, and show that even a brief interaction with a stranger can have a significant impact on memory accuracy and conformity depending on the likability built in that interaction. 


\section{REFERENCES}

Almerigogna, J., Ost, J., Bull, R., \& Akehurst, L. (2007). A state of high anxiety: How non-supportive interviewers can increase the suggestibility of child witnesses. Applied Cognitive Psychology, 21, 963-974. DOI: 10.1002/acp.1311

Andersson, J. (2001). Net effect of memory collaboration: how is collaboration effected by factors such as friendship, gender and age? Scandinavian Journal of Psychology, 42, 367-375. doi: 10.1111/1467-9450.00248

Andersson, J. \& Rönnberg, J. (1995). Recall suffers from collaboration: Joint recall effects of friendship and task complexity. Applied Cognitive Psychology, 9, 199211. doi: 10.1002/acp.2350090303

Andersson, J. \& Rönnberg J. (1997). Cued memory collaboration: effects of friendship and type of retrieval cue. European Journal of Cognitive Psychology, 9, 273-287. doi: $10.1080 / 713752558$

Asch, S. E. (1952). Group forces in the modification and distortion of judgments. In Social Psychology (pp. 330-339). Englewood Cliffs, NJ: Prentice-Hall. doi: 10.1037/10025-016

Baron, R. S., Vandello, J. A., \& Brunsman, B. (1996). The forgotten variable in conformity research: Impact of task importance on social influence. Journal of Personality and Social Psychology, 71, 915- 927. doi: 10.1037/00223514.71.5.915

Carol, R., Carlucci, M., Eaton, A., \& Wright, D. B. (2011, March). The 'power' of a cowitness. Paper presented at the meeting of the American Psychology-Law Society, Miami, Florida.

Collins, R., Lincoln, R., \& Frank, M. G. (2002). The effect of rapport in forensic interviewing. Psychiatry, Psychology, and Law, 9, 69-78. doi: $10.1375 / 132187102760196916$

CPTU (Central Planning and Training Unit). (1992a). A guide to interviewing. Harrogate: Home Office.

CPTU (Central Planning and Training Unit). (1992b). The interviewer's rule book. Harrogate: Home Office.

Deutsch, M., \& Gerard, H. B. (1955). A study of normative and informational social influences upon individual judgment. Journal of Abnormal and Social Psychology, 51, 629-636. doi: 10.1037/h0046408 
Faul, F., Erdfelder, E., Lang, A. G., \& Buchner, A. (2007). G*Power 3: A flexible statistical power analysis program for the social, behavioral, and biomedical sciences. Behavior Research Methods, 39, 175-191. doi: 10.3758/BF03193146

Fisher, R.P., \& Geiselman, R.E. (1992). Memory-enhancing techniques for investigative interviewing: The cognitive interview. Springfield, IL: Charles C. Thomas.

French, L., Garry, M., \& Mori, K. (2008). You say tomato? Collaborative remembering between intimate couples leads to more false memories than collaborative remembering between strangers. Memory, 16, 262-273. doi:10.1080/09658210701801491

Fussell, S. R. \& Krauss, R. M. (1989). Understanding friends and strangers: The effects of audience design on message comprehension. European Journal of Social Psychology, 19, 509-526. doi: 10.1002/ejsp.2420190603

Gabbert, F., Memon, A., \& Allan, K. (2003). Memory conformity: Can eyewitnesses influence each other's memories for an event? Applied Cognitive Psychology, 17, 533-544. doi: 10.1002/acp.885

Gabbert, F., Memon, A., Allan, K., \& Wright, D.B. (2004). Say it to my face: Examining the effects of socially encountered misinformation. Legal and Criminological Psychology, 9, 215-227. doi: 10.1348/1355325041719428

Gabbert, F., Memon, A., \& Wright, D. B. (2006). Memory conformity: Disentangling the steps towards influence during a discussion. Psychonomic Bulletin \& Review, 13, 480-485. Retrieved from http://www.springerlink.com

Gabbert, F., Memon, A., \& Wright, D. B. (2007). I saw it for longer than you: The relationship between perceived encoding duration and memory conformity. Acta Psychologica, 124, 319-331. doi: 10.1016/j.actpsy.2006.03.009

Garry, M., French, L., Kinzett, T. \& Mori, K. (2008). Eyewitness memory following discussion: using the MORI technique with a Western sample. Applied Cognitive Psychology, 22, 431-439. doi: 10.1002/acp.1376

Grahame, F. (2008). 40 icebreakers for small groups. United Kingdom: Creative Commons. Retrieved from http://insight.typepad.co.uk/insight/icebreakers_and_games/.

Hoffman, H. G., Granhag, P. A., See, S., Kwong, T., \& Loftus, E. F. (2001). Social influences on reality-monitoring decisions. Memory \& Cognition, 29, 394-404. Retrieved from http://www.springerlink.com 
Hope, L., Ost, J., Gabbert, F., Healey, S., \& Lenton, E. (2008). “With a little help from my friends": The role of co-witness relationship in susceptibility to misinformation. Acta Psychologica, 127, 476-484. doi: 10.1016/j.actpsy.2007.08.010

Kieckhaefer, J. M., Vallano, J. P., \& Schreiber Compo, N. (2011, March). Rapportbuilding, anxiety, and eyewitness recall: Does rapport-building affect anxiety and witness recall? Paper presented at the meeting of the American Psychology-Law Society, Miami, FL.

Kwong See, S. T., Hoffman, H. G., \& Wood, T. (2001). Perceptions of an old female witness: Is the older eyewitness believable? Psychology \& Aging, 16, 346-350. doi: 10.1037/0882-7974.16.2.346

Loftus, E.F. (1975). Leading questions and the eyewitness report. Cognitive Psychology, 7, 560-572. doi: 10.1016/0010-0285(75)90023-7

Loftus, E. F. (2005). Planting misinformation in the human mind: A 30-year investigation of the malleability of memory. Learning \& Memory, 12, 361-366. doi: $10.1101 / 1 \mathrm{~m} .94705$

Meade, M. L., \& Roediger, H. L., III. (2002). Explorations in the social contagion of memory. Memory \& Cognition, 30, 995-1009. Retrieved from http://www.springerlink.com

Newberry, J. J., \& Stubbs, C. A. (1990). Advanced Interviewing Techniques. Glynco, Georgia: Bureau of Alcohol, Tobacco, and Firearms National Academy.

Paterson, H. M., \& Kemp, R. I. (2006). Comparing methods of encountering postevent information: The power of co-witness suggestion. Applied Cognitive Psychology, 20, 1083-1099. doi:10.1002/acp.1261

Quas, J. A., \& Lench, H. C. (2007). Arousal and encoding, arousal at retrieval, social support, and children's memory for a mild stressor. Applied Cognitive Psychology, 21, 289-305. DOI: 10.1002/acp.1279

Roediger, H. L. (1980). Memory metaphors in cognitive psychology. Memory \& Cognition, 8, 231-246. Retrieved from http://www.springerlink.com

Roediger, H. L., Meade, M. L., \& Bergman, E. T. (2001). Social contagion of memory. Psychonomic Bulletin \& Review, 8, 365-371. Retrieved from http://www.springerlink.com

Schneider, D. M., \& Watkins, M. J. (1996). Response conformity in recognition testing. Psychonomic Bulletin \& Review, 3, 481-485. Retrieved from http://www.springerlink.com 
Skagerberg, E. M., \& Wright, D. B. (2008). Manipulating power can affect memory conformity. Applied Cognitive Psychology, 22, 207-216. doi: 10.1002/acp.1353

Technical Working Group on Eyewitness Evidence. (1999). Eyewitness Evidence: A Guide for Law Enforcement. Washington, DC: U.S. Dept. of Justice, Off. Justice Programs.

Tousignant, J.P., Hall, D., \& Loftus, E.F. (1986). Discrepancy detection and vulnerability to misleading postevent information. Memory and Cognition, 14, 329-338.

Retrieved from http://www.springerlink.com

Vallano, J.P., \& Schreiber Compo, N. (in press). A comfortable witness is a good witness: Rapport-building and susceptibility to misinformation in an investigative mock-crime interview. Applied Cognitive Psychology. doi: 10.1002/acp.1789

Walker, E. L., \& Heyns, R. W. (1962). An anatomy for conformity. Englewood Cliffs, NJ: Prentice Hall.

Wegner, D. M. (1986). Transactive memory: A contemporary analysis of the group mind. In B. Mullen \& G. R. Goethals (Eds.), Theories of group behavior (pp. 185-208). New York: Springer-Verlag.

Wegner, D. M., Erber, R., \& Raymond, P. (1991). Transactive memory in close relationships. Journal of Personality and Social Psychology, 61, 923-929. doi: $10.1037 / 0022-3514.61 .6 .923$

Wright, D. B., \& Davies, G. M. (1999). Eyewitness testimony. In F. T. Durso, Nickerson, R. S., Schvaneveldt, R. W., Dumais, S. T., Lindsay, D. S. \& Chi, M. T. H. (Eds.), Handbook of applied cognition (pp. 789-818). John Wiley \& Sons, Ltd.

Wright, D.B., London, K., \& Waechter, M. (2010). Social anxiety moderates memory conformity in adolescents. Applied Cognitive Psychology, 24, 1034-1045. doi: 10.1002/acp. 1604

Wright, D. B., Mathews, S., A., \& Skagerberg, E. M. (2005). Social recognition memory: The effect of other people's responses for previously seen and unseen items. Journal of Experimental Psychology: Applied, 11, 200-209. doi: 10.1037/1076-898X.11.3.200

Wright, D.B., Memon, A., Skagerberg, E.M., \& Gabbert, F. (2009). When eyewitnesses talk. Current Directions in Psychological Science, 18, 174-178. doi: 10.1111/j.1467-8721.2009.01631.x 
Wright, D.B., \& Schwartz, S.L. (2010). Conformity effects in memory for actions. Memory \& Cognition, 38, 1077-1086. doi: 10.3758/MC.38.8.1077

Wright, D.B., Self, G., \& Justice, C. (2000). Memory conformity: Exploring misinformation effects when presented by another person. British Journal of Psychology, 91, 189-202. doi: 10.1348/000712600161781 
Appendix A

Informed Consent

\section{CONSENT TO PARTICIPATE IN A RESEARCH STUDY}

TITLE: Student Compatibility

The primary purpose of this study is to evaluate how compatible students are with one another. If you decide to participate, you will be one of 240 total people in this research study. If you voluntarily agree to be in the study, we will ask you to do the following things: sign this consent document, fill out some questionnaires, view several photographs of objects, and answer questions about those photographs.

The length of time anticipated for you to complete this study is approximately one hour. Your decision to participate in this study is voluntary and you may terminate your participation at any time without penalty. Upon completion of the study, you will be awarded one credit through Sona Systems.

Your identity and the information that you provide will be kept strictly confidential and will be used only for the purpose of this study. This consent form will be stored separately from your demographic questionnaire in a locked file cabinet at Florida International University. You will be identifiable solely through a numeric code to ensure that your identity remains confidential.

There are minimal risks associated with your participation in this study, which are that you may feel uncomfortable giving out demographic or personal information. If either during or after your participation, you believe that anything you encountered in this study has raised issues or concerns, please contact Jenna Kieckhaefer at jkiec001@fiu.edu or the faculty advisor on the project, Daniel Wright at dwright@fiu.edu.

Participation in this study may benefit you by allowing you to become better informed about your compatibility with other students. This study may benefit society by contributing to the understanding of people's compatibility and memory.

Research at Florida International University involving human participants is carried out under the oversight of the Institutional Review Board (FIU). Information regarding your rights as a research volunteer may be obtained from: Dr. Patricia Price, Office of Research Integrity (FIU), IRB, 305$348-2618$ or $305-348-2494$.

I have read the information in this consent form and agree to participate in this study. I have had a chance to ask any questions I have about this study, and they have been answered for me. I understand that I am entitled to a copy of this form after it has been read and signed.

Signature of Participant

Printed Name of Participant

Signature of Person Obtaining Consent
Date

Date 


\section{Appendix B}

\section{Interview Questions}

1. Where are you from originally? If from Miami how do you like going to school in your home town? If from somewhere else how does Miami compare with your home town?

2. Do you have a pet? (if yes what is it and its name, if no what type of pet would you like)

3. If you could learn any skill, what would it be?

4. Tell me three interesting facts about yourself.

5. What's your favorite TV Show or movie?

6. If you could wish one thing to come true this year, what would it be?

7. What's your favorite thing to do in the summer? 
8. If you could talk to anyone in the world, who would it be? What would you talk about?

9. Would you rather be invisible or be able to read minds?

10. If you could go anywhere in the world where would you go? What would you do?

11. Would you rather be stranded on a deserted island alone or with someone you don't like?

12. Name a gift you will never forget.

13. If you could do your dream job 10 years from now, what would it be?

14. If you HAD to give up one of your senses (hearing, seeing, feeling, smelling, tasting) which would it be and why?

15. If you were sent to live on a space station for three months and only allowed to bring three personal items with you, what would they be? 
Appendix C

\section{Compatibility Questionnaire}

Directions: Rate the other participant on the following characteristics:

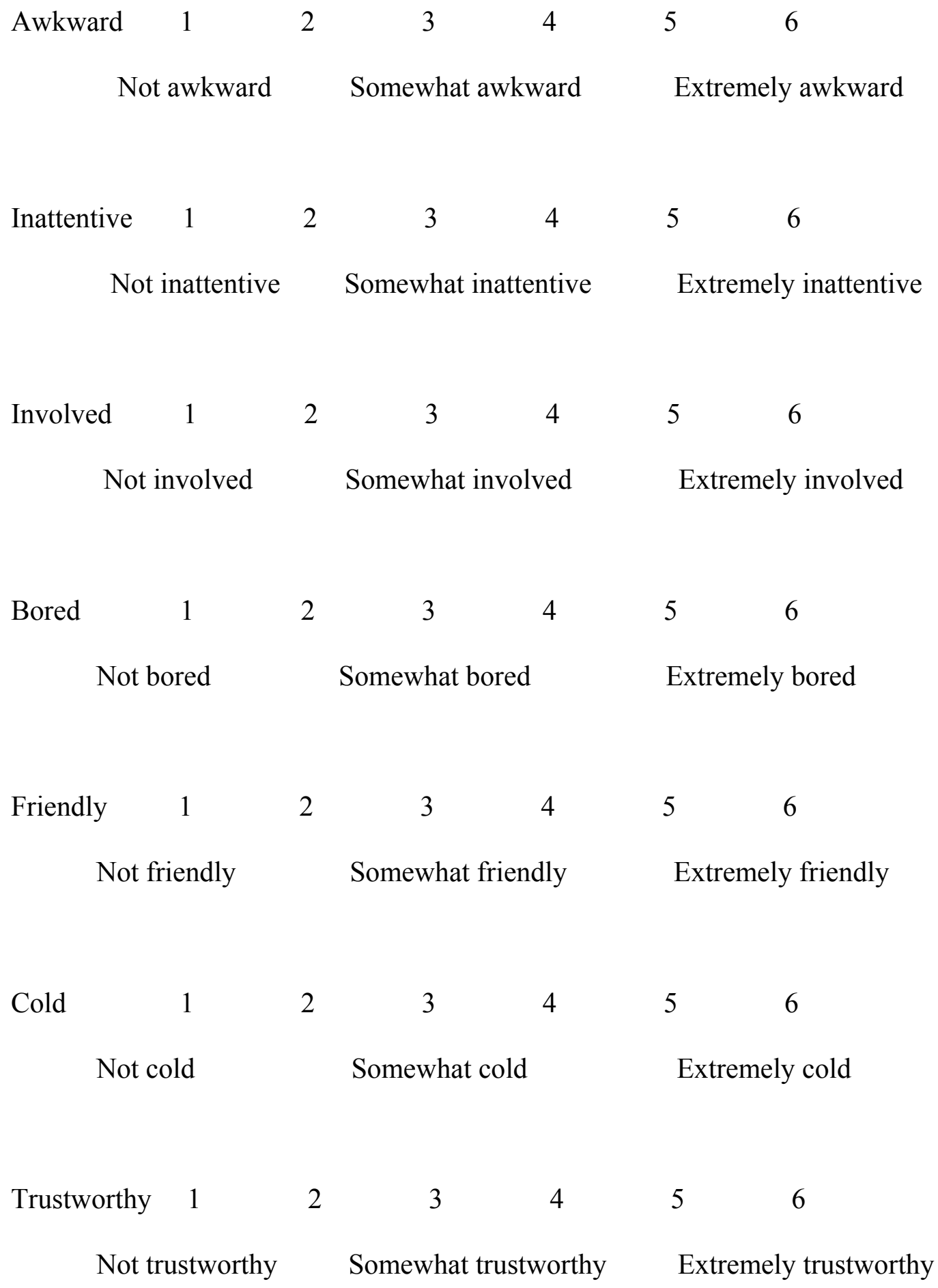




\begin{tabular}{|c|c|c|c|c|c|}
\hline Positive & 1 & 3 & 4 & 5 & 6 \\
\hline \multicolumn{2}{|c|}{ Not positive } & \multicolumn{2}{|c|}{ Somewhat positive } & Ext & y positive \\
\hline Incompetent & 1 & 3 & 4 & 5 & 6 \\
\hline \multicolumn{2}{|c|}{ Not incompetent } & \multicolumn{2}{|c|}{ Somewhat incompetent } & Ext & y incompeten \\
\hline Perceptive & 1 & 3 & 4 & 5 & 6 \\
\hline
\end{tabular}

1. Overall what is your general impression of your co-participant?

$\begin{array}{rrrrrr}1 & 2 & 3 & 4 & 5 & 6 \\ \text { Negative } & & & & & \\ & & & & & \end{array}$

2. How similar do you feel you are to your partner?

$\begin{array}{rrrrrrr}1 & 2 & 3 & 4 & 5 & 6 \\ \text { Dissimilar } & & & & & \\ \end{array}$

3. Overall how would you rate your co participant?

$\begin{array}{lllllll}1 & 2 & 3 & 4 & 5 & 6\end{array}$

Not at all likeable $\quad$ Very likeable

4. How do you believe your partner will evaluate you?

$\begin{array}{rrrrrrr}1 & 2 & 3 & 4 & 5 & 6 \\ \text { Dissimilar } & & & & & & \text { Similar }\end{array}$


Appendix D

Examples of Stimulus Materials
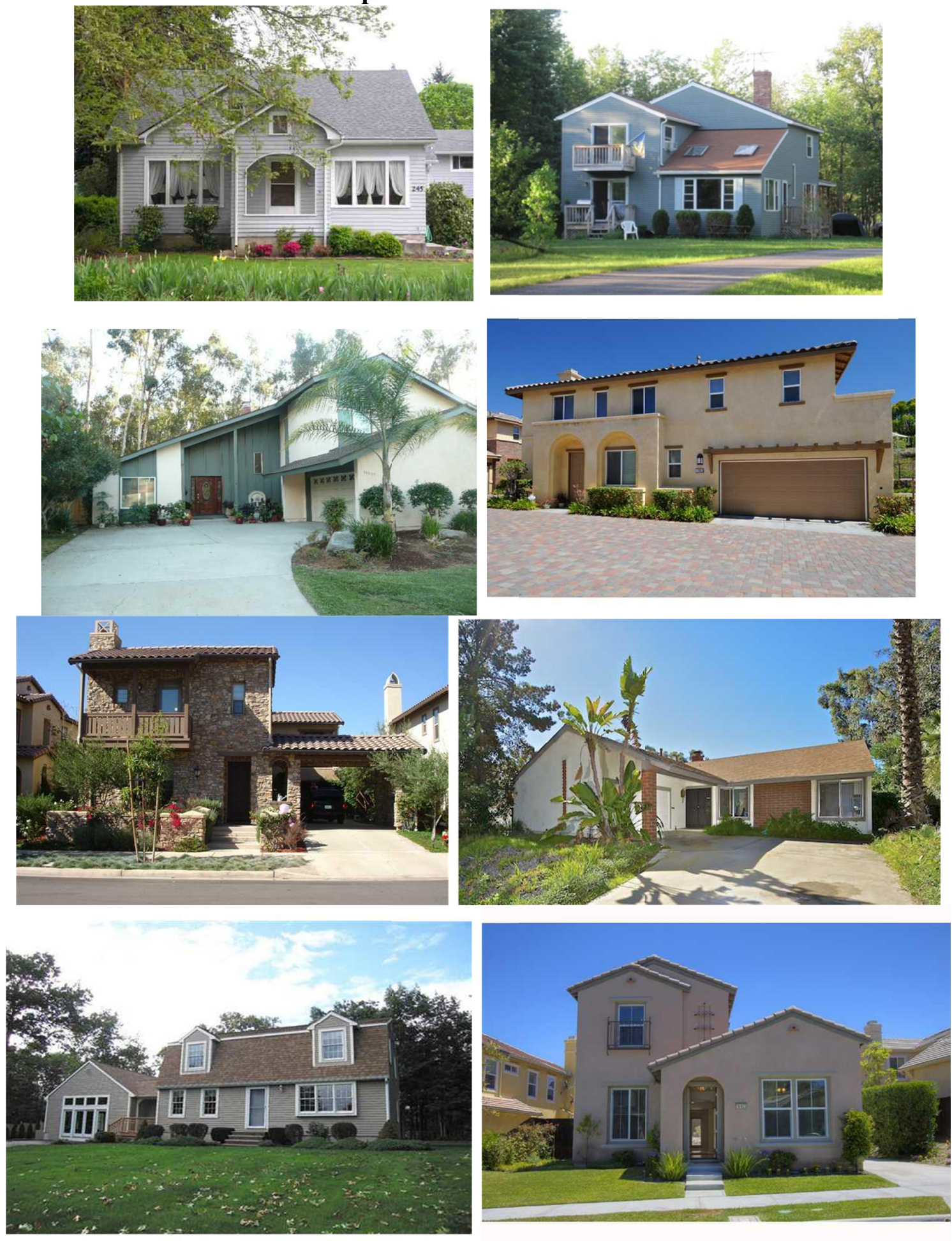


\section{Appendix E}

Filler Task: Word Completion Exercise

\section{USING THE SPACES PROVIDED, PLEASE COMPLETE THE FOLLOWING WORD FRAGMENTS WITH THE FIRST WORD THAT COMES TO YOUR MIND.}

1. $\mathrm{T}$

2. STI

3. TR

4. YE

5. $\mathrm{COFF}$

6. $\mathrm{FO}$

7. SHI

8. CLO

9. SKU

10. $\mathrm{BE}$

11. LI

12. $\mathrm{DE}$

13. COR

14. DRI

15. CHAN

16. GRA

17. TR

18. DA

19. LU
20. MOR

21. FAN

22. DEC

23. $\mathrm{AB}$

24. LIB

25. CORR

26. $\mathrm{WH}_{-}$

27. GA

28. TRU

29. $\mathrm{ACO}$

30. PUN

31. FRA

32. BET

33. WHI

34. VE

35. TUM 
Appendix F

SRT Answer Sheet

\begin{tabular}{|c|c|c|c|c|}
\hline \multirow{2}{*}{$\begin{array}{c}\text { Item Number } \\
\mathbf{1} .\end{array}$} & \multicolumn{2}{|c|}{ Participant 1} & \multicolumn{2}{|c|}{ Participant 2} \\
\hline & Old & New & Old & New \\
\hline 2. & Old & New & Old & New \\
\hline 3. & Old & New & Old & New \\
\hline 4. & Old & New & Old & New \\
\hline 5. & Old & New & Old & New \\
\hline 6. & Old & New & Old & New \\
\hline 7. & Old & New & Old & New \\
\hline 8. & Old & New & Old & New \\
\hline 9. & Old & New & Old & New \\
\hline 10. & Old & New & Old & New \\
\hline 11. & Old & New & Old & New \\
\hline 12. & Old & New & Old & New \\
\hline 13. & Old & New & Old & New \\
\hline 14. & Old & New & Old & New \\
\hline 15. & Old & New & Old & New \\
\hline 16. & Old & New & Old & New \\
\hline 17. & Old & New & Old & New \\
\hline 18. & Old & New & Old & New \\
\hline 19. & Old & New & Old & New \\
\hline 20. & Old & New & Old & New \\
\hline 21. & Old & New & Old & New \\
\hline 22. & Old & New & Old & New \\
\hline 23. & Old & New & Old & New \\
\hline 24. & Old & New & Old & New \\
\hline 25. & Old & New & Old & New \\
\hline 26. & Old & New & Old & New \\
\hline 27. & Old & New & Old & New \\
\hline 28. & Old & New & Old & New \\
\hline 29. & Old & New & Old & New \\
\hline 30. & Old & New & Old & New \\
\hline 31. & Old & New & Old & New \\
\hline 32. & Old & New & Old & New \\
\hline 33. & Old & New & Old & New \\
\hline 34. & Old & New & Old & New \\
\hline 35. & Old & New & Old & New \\
\hline 36. & Old & New & Old & New \\
\hline 37. & Old & New & Old & New \\
\hline 38. & Old & New & Old & New \\
\hline 39. & Old & New & Old & New \\
\hline 40. & Old & New & Old & New \\
\hline 41. & Old & New & Old & New \\
\hline 42. & Old & New & Old & New \\
\hline 43. & Old & New & Old & New \\
\hline 44. & Old & New & Old & New \\
\hline 45. & Old & New & Old & New \\
\hline 46. & Old & New & Old & New \\
\hline 47. & Old & New & Old & New \\
\hline 48. & Old & New & Old & New \\
\hline
\end{tabular}




\begin{tabular}{|c|c|c|c|c|}
\hline 49. & Old & New & Old & New \\
\hline 50. & Old & New & Old & New \\
\hline 51. & Old & New & Old & New \\
\hline 52. & Old & New & Old & New \\
\hline 53. & Old & New & Old & New \\
\hline 54. & Old & New & Old & New \\
\hline 55. & Old & New & Old & New \\
\hline 56. & Old & New & Old & New \\
\hline 57. & Old & New & Old & New \\
\hline 58. & Old & New & Old & New \\
\hline 59. & Old & New & Old & New \\
\hline 60. & Old & New & Old & New \\
\hline 61. & Old & New & Old & New \\
\hline 62. & Old & New & Old & New \\
\hline 63. & Old & New & Old & New \\
\hline 64. & Old & New & Old & New \\
\hline 65. & Old & New & Old & New \\
\hline 66. & Old & New & Old & New \\
\hline 67. & Old & New & Old & New \\
\hline 68. & Old & New & Old & New \\
\hline 69. & Old & New & Old & New \\
\hline 70. & Old & New & Old & New \\
\hline 71. & Old & New & Old & New \\
\hline 72. & Old & New & Old & New \\
\hline 73. & Old & New & Old & New \\
\hline 74. & Old & New & Old & New \\
\hline 75. & Old & New & Old & New \\
\hline 76. & Old & New & Old & New \\
\hline 77. & Old & New & Old & New \\
\hline 78. & Old & New & Old & New \\
\hline 79. & Old & New & Old & New \\
\hline 80. & Old & New & Old & New \\
\hline 81. & Old & New & Old & New \\
\hline 82. & Old & New & Old & New \\
\hline 83. & Old & New & Old & New \\
\hline 84. & Old & New & Old & New \\
\hline 85. & Old & New & Old & New \\
\hline 86. & Old & New & Old & New \\
\hline 87. & Old & New & Old & New \\
\hline 88. & Old & New & Old & New \\
\hline 89. & Old & New & Old & New \\
\hline 90. & Old & New & Old & New \\
\hline 91. & Old & New & Old & New \\
\hline 92. & Old & New & Old & New \\
\hline 93. & Old & New & Old & New \\
\hline 94. & Old & New & Old & New \\
\hline 95. & Old & New & Old & New \\
\hline 96. & Old & New & Old & New \\
\hline 97. & Old & New & Old & New \\
\hline 98. & Old & New & Old & New \\
\hline 99. & Old & New & Old & New \\
\hline 100. & Old & New & Old & New \\
\hline
\end{tabular}


Appendix G

\section{Demographics Questionnaire}

1. What is your age? Years

2. What is your gender?

Check one: Male Female

3. Which of the following categories best reflects your ethnic/racial identity? (check only one)

African American
Caucasian: Non-Hispanic
Native American

Asian/Pacific Islander
Hispanic
Other

4. What is the highest education level you have completed?

high school graduate

freshman year in college sophomore year in college none of the above

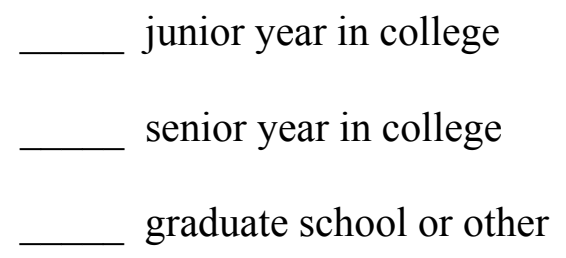

graduate school or other

5. Is English your primary/native language? Yes No If no, how long have you spoken English fluently? Years If no, what is your native language? 


\section{Appendix $\mathrm{H}$}

\section{Debriefing Statement}

Thank you for your participation. The purpose of the present study is to assess how likeability influences memory recall accuracy. Although many variables are known to affect memory accuracy, little is known about what happens between strangers after liking is built. We are testing different levels of liking to see how they affect memory conformity with another person and overall memory accuracy.

This research seeks to help both psychologists and investigative interviewers, such as police detectives, elicit more accurate information from witnesses and victims of crime. Specifically, examining the relationship between liking or disliking of previously unacquainted individuals and memory accuracy may be helpful. The results of this study will have implications for training investigative interviewers and informing witness interview guidelines.

If you should have any questions or concerns regarding the study and your role in it, please do not hesitate to contact the principal investigator, Jenna Kieckhaefer at jkiec001@fiu.edu. If you experienced any discomfort associated with the study and would like to speak to a counselor free of charge, you may contact FIU Counseling and Psychological Services Center at 305-348-2434.

Thank you again for your time and participation. 